\title{
LENGUAJE Y SÍMBOLO: EL $\$ 59$ DE LA CRÍTICA \\ DE LA FACULTAD DE JUZGAR EN VERDAD Y MÉTODO
}

\author{
Daniel LESERRE \\ Consejo de Investigaciones Científicas y Técnicas
}

\begin{abstract}
RESUMEN. El presente trabajo se ocupa de la recepción por Gadamer de la concepción kantiana del símbolo. En primer lugar analiza los aspectos centrales de la concepción kantiana a través de la relación entre esquematismo, simbolismo y lenguaje. En segundo término, identifica la recepción de la noción kantiana de símbolo por parte de Gadamer. Finalmente, evalúa el significado de esta recepción al sostener que ella comparte en buena medida la posición de Kant, para ir más allá de ella en el sentido de una "ontología del símbolo".
\end{abstract}

El examen de la «subjetivización de la estética» por la crítica de Kant ${ }^{1}$ culmina con la consideración de la noción de símbolo. Allí Gadamer caracteriza al «análisis lógico del concepto de símbolo" llevado a cabo en el $\$ 59$ de la Crítica de la facultad de juzgar como "uno de los más brillantes del pensamiento kantiano" ${ }^{2}$. En Verdad y método Gadamer recibe, asume y desarrolla desde su perspectiva hermenéutica la concepción kantiana del simbolismo. El propósito del presente trabajo consiste en presentar el núcleo de esta concepción de Kant y mostrar su reapropiación por parte de Gadamer.

${ }^{1}$ Cf. H.-G. Gadamer, Wahrheit und Methode, J. C B. Mohr (3.' ed.), Tubinga, 1972, 39-77 (a partir de ahora citada como WuM). Cito la Critica de la razón pura y la Critica de la facultad de juzgar en la versión B, respectivamente según I. KANT, Kritik der reiner Vernunft, F. Meiner, Hamburgo, 1956 (a partir de ahora citada como $K r V$ ), e I. KaNT, Kritik der Urteilkskraft, F. Meiner, Hamburgo, 1974 (a partir de ahora citada como $K U$ ). A las otras obras de Kant me refiero según I. KanT, Gesammelte Schriften, Preussischen Akademie der Wissenschaften, Berlín, 1902-1910; Berlín, 1968-1977. Vorlesungen ed. von der Akademie der Wissenschaften zu Göttingen, vol. 24 ss. (a partir de ahora citada como AA, tomo, página).

${ }^{2} W u M, 71$. 
Para Gadamer la problemática propia de la estética kantiana se mueve en torno de "la significatividad interesada de lo bello" ${ }^{3}$. En este marco, su recepción de la concepción kantiana del símbolo puede ser identificada por medio de las siguientes afirmaciones ${ }^{4}$.

a) La «exhibición simbólica» (symbolische Darstellung) es contrapuesta por Kant a la "exhibición esquemática»; especificando que ella es "exhibición (y no mera designación como en el denominado 'simbolismo' lógico)" ${ }^{5}$.

b) Pero a diferencia de la exhibición esquemática (la cual es directa), la exhibición simbólica es una forma indirecta de brindar intuición al concepto.

c) El símbolo indica el límite del concepto. Con ello, sostiene Gadamer, Kant hace honor a la "verdad teológica» contenida en la idea de la analogia entis, la cual establece una distancia entre los conceptos humanos y Dios ${ }^{6}$.

d) Kant identifica de una manera explícita la presencia de la dimensión simbólica en el lenguaje por medio del permanente proceso de elaboración metafórica que tiene lugar en este.

e) Kant emplea el concepto de analogía para establecer una relación entre lo bello y el bien moral; esta relación, sin ser de subordinación, tampoco es una relación de equivalencia, entre dos elementos en el mismo plano.

Estas afirmaciones no pretenden representar exhaustivamente la recepción de la concepción kantiana del simbolismo por parte de Gadamer, sino brindar el marco básico para el siguiente análisis; el cual se desarrollará primero considerando la cuestión en la Critica de la facultad de juzgar, para luego retornar a Verdad y método.

\section{Esquematismo y simbolismo}

El $\$ 59$ ubica al lenguaje en el marco del examen de la relación entre concepto e intuición. Su inicio indica claramente el problema que nos ocupa:

$3 W u M, 46$.

${ }^{4}$ CF. $W u M, 69-71$.

5 WuM, 71.

${ }^{6}$ Ibíd. 
Para exhibir la realidad de nuestros conceptos se exigen siempre intuiciones. Si los conceptos son empíricos, entonces llámanse la intuiciones ejemplos; si son conceptos puros del entendimiento, llámanse esquemas; si se pide que se exhiba la realidad objetiva de los conceptos de la razón, es decir, de las ideas y ello para el conocimiento teórico de las mismas, entonces se desea algo imposible porque no puede, de ningún modo, darse intuición alguna que les sea adecuada ${ }^{7}$.

La determinación teórica del concepto de lenguaje se halla en la mutua relación entre concepto e intuición. Pero precisamente tal es el problema del posible significado de los conceptos. Las formas de procurarles significado a estos son, desde la perspectiva trascendental, el esquematismo y el simbolismo. Partimos entonces, tal como lo indica el pasaje citado, de cómo los conceptos pueden alcanzar significado y de la comparación entre las dos formas fundamentales de lograrlo: esquematismo y simbolismo. Recordemos brevemente la función del esquematismo. La doctrina kantiana del esquematismo surge, en primer término, como respuesta al problema clásico de la relación entre entendimiento y sensibilidad. En general, el esquematismo es, en tanto producto de la imaginación, el modo de relacionar entendimiento y sensibilidad. El esquema es «un procedimiento universal de la imaginación» a través del cual «se le suministra a un concepto su propia imagen" ${ }^{8}$. Ahora bien, el esquematismo comparte con el lenguaje el ser un producto de la imaginación y servir como mediación entre entendimiento y sensibilidad, pero como función trascendental muestra su diferencia respecto de él. La doctrina del esquematismo, entonces, si bien no se refiere directamente al lenguaje, ofrece una determinación respecto del "lugar» que se le asigna al lenguaje "entre" entendimiento y sensibilidad. Precisamente lenguaje y esquemas son productos de la imaginación, pero estos últimos, a diferencia de los signos del lenguaje, son el resultado de la imaginación trascendental. Los signos lingüísticos, por su parte, se caracterizan por resultar de la asociación, cuyo carácter es empírico. Los esquemas trascendentales son formas temporales universales de vincular concepto e intuición; la facultad de los signos, a su vez, sólo produce asociaciones diversas y contingentes, cuya estabilidad está dada por el hábito ${ }^{9}$. Pero de

${ }^{7} K U, \mathrm{~B} 254$.

${ }^{8} \mathrm{KrV}, \mathrm{B} 179$.

9 Al lenguaje como facultad de designación se refiere Kant en varias partes. La Antropologia en sentido pragmático, particularmente en el $\$ 38$, constituye la referencia básica. 
este modo, por así decir, por contrapartida, la doctrina kantiana del esquematismo indica que el esquematismo, y como veremos, el simbolismo, implican una perspectiva trascendental respecto del lenguaje. Las consideraciones críticas de J. G. Hamann y J. G. Herder a la Crítica de la razón pura respecto de la ausencia de una consideración del lenguaje por parte de la filosofía crítica y la posición de ambos de que el esquematismo es el "lugar» de la teoría de Kant donde debía ubicarse la reflexión acerca del lenguaje confirman, entonces, indirectamente, como el esquematismo (y consecuentemente el simbolismo) es el marco adecuado en la conceptualización de Kant para la discusión acerca del lenguaje ${ }^{10}$. El simbolismo, por su parte, desempeña una función semejante al esquematismo, su importancia como concepto teórico se muestra resaltada a través de este paralelismo. Desde el punto de vista de su función mediadora entre concepto e intuición la caracterización que acabamos de hacer del esquematismo se aplica al simbolismo.

\section{El lenguaje en la perspectiva del simbolismo}

Concepto e intuición pueden relacionarse, entonces, de diferentes modos según el tipo de concepto del que se trate y de la forma según la cual se le brinde intuición al concepto. En el caso del esquematismo al concepto originado en el entendimiento le es dada a priori una intuición correspondiente; mientras que en el simbolismo, el concepto originado en la razón no encuentra intuición sensible alguna que pueda corresponderle ${ }^{11}$. Dada esta carencia de una intuición correspondiente que pueda ser subordinada al concepto por medio del esquema, la facultad de juicio procede entonces de una manera analógica. En el procedimiento analógico un concepto es referido a su posible objeto pero, en ausencia de una intuición correspondiente, esta referencia tiene lugar a través de otro concepto, al cual sí le es dada una intuición. Este tipo de representación simbólica es intuitiva y no discursiva. Por ello, si bien en ciertas ocasiones Kant emplea el

${ }^{10}$ Ambos conciben el esquematismo como el concepto kantiano que, en tanto instancia de mediación entre la sensibilidad y el entendimiento, permite comprender la función del lenguaje, aun cuando Kant no planteara explícitamente esta equivalencia entre esquematismo y lenguaje. Herder propone una "metacrírica" de la filosofía kantiana, entendiendo por tal una crítica de la razón que estaría no meramente orientada al aspecto formal de la misma, sino también a la determinación de los contenidos que podrían serle propios. Herder lleva a cabo este proyecto en su "metacrítica" de la Critica de la razón pura: T. M. SEEBOHM «Der systematische Ort der Herderschen Metakritik», Kant-Studien, 63, 1972, 59-74.

11 Para presentar la comparación me refiero ahora a este caso y no a las ideas estéticas. 
término "símbolo" en un sentido general ${ }^{12}$, aquí aparece en su determinación específica como presentación, aun cuando indirecta, de un objeto. En este sentido, afirma Kant que "símbolo" en el sentido aquí tratado difiere del «admitido por los lógicos modernos" ${ }^{13}$, puesto que para ellos símbolos son meros caracteres, es decir, designaciones de los conceptos por medio de notas sensibles que los acompañan. Como meros caracteres (palabras, signos algebraicos o gestos) no contienen nada que pertenezca a la intuición del objeto, sino que sólo sirven a los conceptos como medio de reproducción según la asociación de la imaginación, por lo tanto, en intención subjetiva, son meras expresiones para los conceptos $^{14}$.

La representación simbólica es, como dijimos, intuitiva. La exhibición intuitiva de una representación puede ser entonces intuitiva en sentido propio o simbólica. Ambas son exhibiciones en todo el sentido del término, esto es, formas de presentar un objeto. Por referirse indirecta pero efectivamente a intuiciones, el procedimiento simbólico es considerado como una forma de «conocimiento intuitivo" que se opone al discursivo; y el símbolo es una forma de exhibición indirecta pero intuitiva. En este contexto, entonces, lejos de "caracterizar la razón abstracta, el símbolo pertenece a la manera intuitiva y sensitiva de aprehender las cosas" ${ }^{15}$.

Todas las intuiciones que se ponen bajo conceptos a priori son esquemas o símbolos de los cuales los primeros contienen exhibiciones directas del concepto, los segundos indirectas. Los primeros hacen esto demostrativamente; los segundos por medio de una analogía (para la cual también se utilizan intuiciones empíricas) ${ }^{16}$.

Los símbolos contienen exhibiciones indirectas por medio de la analogía. El símbolo adquiere de este modo significado en relación con lo que puede pensar-

${ }^{12}$ Así, por ejemplo, habla de «construcción simbólica» en el contexto de las operaciones matemáticas; $K r V, \mathrm{~B} 745$.

${ }^{13} K U, \mathrm{~B} 255$.

${ }_{14} K U$, B 255. Dicho de otro modo, es la diferencia entre signo y símbolo. Esta idea es expresada también en la Antropologia en sentido pragmático; cfr. I. KANT, Anthropologie in pragmatischer Hinsicht, AA, VI, 191.

${ }^{15}$ T. TODOROV, Theories du Symbole, Du Seuil, París, 1977, 236.

${ }^{16} K U$, В 256. 
se a partir de él, a partir de lo que puede «verse» en él. Ello puede ejemplificarse a través de la observación kantiana respecto de la palabra "demostrativamente" (demonstrativ). Indica Kant que la emplea manteniendo, al menos parcialmente, el «significado de la palabra» según el cual "demostrar (ostendere, exhibere)" significa simultáneamente exhibir un concepto en la intuición ${ }^{17}$. De este modo, Kant indica el carácter sensible del símbolo. En este sentido el simbolismo desempeña una función semejante al esquematismo. En el simbolismo se produce también una relación entre entendimiento y sensibilidad por medio de la imaginación, pero aquí por medio de la analogía. El modo de proceder en la forma simbólica de esquematizar se ve particularmente ilustrado por la analogía. La representación analógica se funda en la función de la capacidad reflexionante de juzgar (mientras que el esquematismo se realiza en la función determinante). En ella la capacidad de juzgar ejecuta una doble operación; en primer lugar aplica el concepto al objeto de una intuición y, en segundo término, yendo más allá de esta, emplea la regla de la reflexión, aplicada en el primer caso, a otro objeto completamente distinto del cual el primer concepto es sólo un símbolo. El lenguaje como tal se configura según este procedimiento que relaciona concepto e intuición:

Nuestra lengua está llena de semejantes exhibiciones indirectas, según una analogía, en las cuales la expresión no encierra propiamente el esquema para el concepto, sino un símbolo para la reflexión. Así, las palabras fundamento (apoyo, base), depender (ser tenido desde arriba), fluir a partir de (en vez de seguirse), substancia (el portador de los accidentes según se expresa Locke) e innumerables más, no son hipotiposis esquemáticas, sino simbólicas, y son expresiones para conceptos, no por medio de una intuición directa, sino sólo según la analogía con la misma, es decir según la translación de la reflexión, de un objeto de la intuición, a otro concepto totalmente distinto, al cual quizá no pueda jamás corresponder una intuición ${ }^{18}$.

Kant ilustra el funcionamiento del lenguaje a través de ejemplos del léxico filosófico. En la palabra "fundamento" se sugiere la imagen de apoyo, de base; en "depender" la de estar sostenido. La palabra "sustancia» induce la imagen del

\footnotetext{
${ }^{7} K U, \mathrm{~B} 241$.

${ }^{18} K U, \mathrm{~B} 257$.
} 
portador de algo. El lenguaje entonces, en tanto simbolismo, cumple con la función de volver sensible al concepto; brinda, por medio de imágenes asociadas analógicamente, un acceso a los conceptos. En tanto exposición simbólica el lenguaje brinda al concepto aquello que la razón sólo puede pensar: una integración específicamente estética a través de la determinación analógica del concepto. El lenguaje como tal suministra imágenes en las cuales se manifiesta lo inteligible $^{19}$. De este modo, bajo el título de simbolismo, se sintetiza una perspectiva unificadora de la reflexión kantiana sobre el lenguaje, la cual aparece aquí en el marco de la idea de una determinación inteligible del ser humano, a la cual se arriba a través de la «belleza como símbolo de la moralidad» ${ }^{20}$. Con ello se brinda indirectamente la identificación de una función del lenguaje ya no meramente "intralingüística", la relación entre signos a través de la asociación, sino referencial. El simbolismo enfoca el lenguaje desde el punto de vista de la posible significación de los conceptos, aun cuando esta sólo pueda ser indirecta.

\section{Simbolismo y posibilidad de comunicación}

En tanto a través del símbolo no se llega a establecer una realidad objetiva para nosotros, sino indirectamente una forma de intuición por medio de una analogía, queda abierta la posibilidad de perspectivas respecto de lo que es, así como queda abierta la posibilidad de comunicación de las mismas ${ }^{21}$. Comunicación aquí no es un concepto estrictamente lingüístico, sino que forma parte de la crítica trascendental. Desde el punto de vista de la argumentación referida al lenguaje con el concepto de comunicación, la Crítica de la facultad de juzgar retoma la cuestión allí donde la había dejado la Crítica de la razón pura: «Nada puede ser universalmente comunicado más que el conocimiento y la representación en cuanto pertenece al conocimiento" ${ }^{22}$. En la Critica de la facultad de juz-

${ }^{19} \mathrm{~W}$. Flach afirma que «el lenguaje se recubre con el dominio de la representación intuitivosimbólica" (W. FLACH: "Zu Kants Lehre von der symbolischen Darstellung», Kant-Studien, 73, 1982,458 ). A partir de ello subraya la importancia del lenguaje como acceso a lo inteligible. Ve en ello una de las contribuciones de la doctrina kantiana de la exposición simbólica a la filosofía del lenguaje y la teoría de la ciencia literaria (ibid., 458 y 459).

$20 K U$, В 258.

21 Precisamente al referirse a la noción de analogia, concepto en el cual convergen la consideración acerca del lenguaje y del símbolo, afirma Kant que se trata de un tema apenas analizado, aun cuando merecería una "profunda indagación"; pero lo deja sin desarrollar: $K U, \mathrm{~B} 257$.

${ }^{22} K U, \mathrm{~B} 27$. 
gar la discusión del juicio de conocimiento da paso a la discusión de la posible objetividad del juicio estético. En este caso, en tanto el juicio estético pretende una universalidad y necesidad para todo sujeto, también requiere una deducción, es decir, una legitimación que descanse en un principio a priori. El resultado no es, precisamente, la objetividad, puesto que «el juicio de gusto determina su objeto", no ya como objetivo sino "como si fuese objetivo»". Aquí la «intuición" está dada por la imaginación que "esquematiza sin concepto» ${ }^{24}$.

La comunicación, en consonancia con ello, es analizada desde el punto de vista de la posible comunicación de las ideas estéticas, las cuales no pueden ser integralmente expresadas por ningún lenguaje. La posibilidad de comunicación universal plantea, entonces, los límites mismos del lenguaje: el de la expresión de lo inefable, tal como se manifiesta al tratar de comunicar las ideas estéticas ${ }^{25}$. Estas son representaciones de la imaginación que inducen al pensamiento sin poder, sin embargo, ser determinadas y precisadas en un concepto. Por ello «ningún lenguaje puede alcanzar plenamente» la idea estética y "hacerla comprensible» ${ }^{26}$. La reflexión sobre la idea estética señala el límite de una posibilidad de comunicación más allá del concepto, y con ello los límites del lenguaje. La idea estética comunica, da pie para pensar en algo más allá de lo que las palabras pueden expresar de su concepto, puesto que ella consiste en «atributos (estéticos) de un objeto cuyo concepto, como idea de la razón, no puede ser expuesto adecuadamente» ${ }^{27}$. La idea estética se halla asociada a representaciones como resultado del libre uso de la imaginación, y al no encontrar una expresión que indique un determinado concepto, whace, pues, que en un concepto pensemos muchas cosas innombrables, cuyo sentimiento vivifica las facultades de conocer, y se enlaza al lenguaje, en tanto mera letra" ${ }^{28}$.

${ }^{23} K U, \mathrm{~B} 136$.

${ }^{24} K U, \mathrm{~B} 146$

25 "Semejantes representaciones de la imaginación pueden ser llamadas ideas; por una parte porque tienden, al menos, a algo que se halla sobre los límites de la experiencia, y así buscan aproximarse a una exhibición de los conceptos de la razón (de las ideas intelectuales), lo cual les da la apariencia de una realidad objetiva; por otro lado y, fundamentalmente, porque en cuanto intuiciones internas ningún concepto puede serles enteramente adecuadon ( $K U, \mathrm{~B} 193-194)$.

${ }^{26} K U \mathrm{~B}, 193$

${ }^{27} K U, \mathrm{~B} 195$. Los atributos estéticos «dan también una idea estética, que en lugar de la exhibición lógica de aquella idea de la razón, sirve propiamente para vivificar el alma en la medida en que le abre la perspectiva en un imprevisible campo de representaciones afines" ( $K U, \mathrm{~B} 195)$.

${ }^{28} K U, \mathrm{~B} 197$. 
Ello aparece claramente en la poesía. Aquí la reflexión sobre el lenguaje tiene lugar en tanto éste se realiza como arte. Si bien la poesía sólo ofrece un juego de ideas, da vida, por medio de la imaginación, a los conceptos producidos por el entendimiento. Ella expresa las ideas estéticas por medio del lenguaje y, en este sentido, resume por excelencia (en cierto sentido "doblemente», como arte y como lenguaje) la exhibición simbólica que, común a todo arte, caracteriza, como hemos visto, también al lenguaje $\mathrm{e}^{29}$. El lenguaje poético permite comunicar una disposición subjetiva del ánimo y simultáneamente manifestar el principio que le confiere vida: el espíritu. A partir de ello, entonces, el lenguaje es visto en relación con la posibilidad de comunicación. La analítica en la Crítica de la razón pura mostró que no hay significado trascendental sino significado "para nosotros», que el mundo es común como significado objetivo para nosotros. La analítica de lo bello en la Crítica de la facultad de juzgar muestra que sobre esa base objetiva, establecida en la Crítica de la razón pura, y más allá de ella, se dan otras posibilidades de referirse a los objetos; posibilidades abiertas por la libertad. En ellas la subjetividad comunica perspectivas expresadas en el juicio de gusto. Pero esta posibilidad abierta en la reflexión acerca del arte no consiste meramente en la posibilidad de expresión de la subjetividad, sino que pretende tener un fundamento, el cual se expresa en la universalidad postulada en el juicio de gusto. Los juicios acerca de los objetos bellos, a diferencia de los juicios acerca de fenómenos que simplemente puedan ejercer un efecto agradable (y que, en consecuencia, sólo pueden pretender una validez privada), deben poder establecer una concordancia con los juicios de otros. Por ello, al juicio de gusto se le asocia con una pretensión de validez para todos, pero esta universalidad no se halla apoyada en objetos, sino que se halla ligada a «una pretensión de universalidad subjetivan ${ }^{30}$. Este juicio tiene, entonces, la tarea de combinar las dos características propias del juicio de conocimiento (universalidad y necesidad) con las que lo distinguen como juicio de gusto: subjetividad y falta de concepto. Mientras en el juicio de conocimiento se establece una "realidad objetiva", en el juicio de gusto se comunican "objetividades móviles», símbolos, obras que abren valoracio-

29 En ella el pensamiento se daría, por así decir, cifrado. En este sentido la poesía sería una forma previa de reflexión. Esto puede ilustrarse con el siguiente pasaje de la Lógica: "Por lo demás los primeros filósofos expresaron todo en imágenes. Pues la poesía, que no es otra cosa que una expresión de los pensamientos en imágenes, es más antigua que la prosa. Por ello, al comienzo, incluso en las cosas que sólo son objeto de la razón pura, se tuvo que hacer uso del lenguaje de las imágenes y de la forma de escribir poética» (I. KANT: Logik, AA, IX, 146).

\footnotetext{
${ }^{30}$ Cf. $K U$, B 21.
} 
nes y perspectivas (acerca de lo dado sensiblemente). Aquí el juicio no es necesario y universal, sino que comunica posibilidades orientadas por las ideas estéticas. Ahora en el lugar del objeto aparece "otra cosa», que da qué pensar; referirse a algo ahora es entonces "abrir posibilidades»" ${ }^{31}$. Aquí, ahora, el significado no puede ser establecido como "realidad objetiva" (universal y necesaria), sino que se construye para nosotros, determinado según la idea, la cual siendo la misma para todos es al mismo tiempo subjetiva, individual. Así, mediada por la referencia individual a la idea, la posibilidad de comunicación universal se construye "más allá" del significado objetivo. Aquí el juicio no determina objetos, sino que reflexiona libremente a partir de las ideas realizadas estéticamente, las cuales "dan para pensar infinitamente" ${ }^{32}$. En la obra de arte se realiza la subjetividad como libertad. Pero en la caracterización de "subjetivo" en el juicio de gusto se halla ya simultáneamente implicada la remisión a una comunidad de sujetos ${ }^{33}$. En la obra de arte se muestra la posibilidad de comprenderse universalmente. De este modo se señala desde una perspectiva trascendental el fundamento de la sociabilidad humana, ya que "humanidad significa [...] la facultad de poder comunicarse íntima y universalmenten ${ }^{34}$.

Para concluir, mientras según la Critica de la razón pura entre el entendimiento y la sensibilidad media el esquema, según la Crítica de la facultad de juzgar media el símbolo. Da acuerdo a la Crítica de la facultad de juzgar, dada la imposibilidad de intuir directamente el objeto, quedan abiertas las posibilidades

31 De este modo el arte se transforma en una especie de orientación vital, puesto que en la producción o juicio de las obras de arte al mismo tiempo «me vuelvo consciente de que ellas son productos, posiciones subjetivas, y las capto como posibilidades a las cuales puedo orientar mi vida, aun cuando no sean como objetos para ser conocidos o como perspectivas éticas para ser fundadas" (U. MÜLLER, "Objektivität und Fiktionalität", Kant-Studien, 77, 1986, 212).

${ }^{32} K U, \mathrm{~B} 192$

33 Tal como señala U. Müller, quien agrega: «Tal empleo de la palabra subjetivo no es (o al menos no completamente) consciente para Kant, pero podemos estar autorizados a sacar esta consecuencia" (U. MÜLLER, op. cit., 205). "La explicación del concepto kantiano de subjetividad estética demuestra sus relaciones indirectas con un concepto de intersubjetividad no expresamente nombrado como tal, que sin embargo debe ser pensado en él" (ibíd.). A su vez, "la relación de la parte referida al entendimiento y la parte no referida al entendimiento representada por la imaginación, la relación de estas dos maneras de representar, es lo que da la posibilidad de comunicabilidad universal de las representaciones estéticas. En este sentido habría una 'objetividad' estética que en un sentido 'débil' es comprendida como intersubjetividad» (ibíd., 207).

${ }^{34} K U, \mathrm{~B} 252$. 
de intuir indirectamente, es decir, de pensar analógicamente y de comunicarse. Pero con ello entonces se afirma, desde el punto de vista trascendental, la legitimidad de la diversidad de interpretaciones posibles sostenidas en el juicio de gusto. Según la Critica de la facultad de juzgar, el juicio reflexiona a partir de símbolos y establece analogías que son diversas, sin tratarse de una diversidad meramente empírica. En este sentido la analítica de lo bello ofrece un modelo para comprender la diversidad lingüística en el marco de una racionalidad pura, pero no determinante sino reflexionante. Desde este punto de vista el lenguaje en tanto símbolo da qué pensar. La reflexión filosófica de Kant acerca del lenguaje, en tanto idealismo trascendental, deja necesariamente abierta, entonces, la posibilidad de comprender el lenguaje como lo que va "más allá» del mundo como significado, es decir, deja abierta la posibilidad del símbolo, en tanto este testimonia lo inexpresable.

\section{La recepción hermenéutica de la noción kantiana de símbolo}

El examen llevado hasta aquí se refiere a las tesis indicadas al comienzo siguiendo la idea de simbolismo. Si bien deja importantes aspectos, como el de la belleza como símbolo de la moralidad, permite, sin embargo, indicar la reapropiación de dicha idea por parte de la hermenéutica de Gadamer. Esta reapropiación puede ser descrita como el movimiento teórico que conduce de la reflexión trascendental en Kant al desarrollo de una ontología del símbolo. Tal como dijimos al comienzo del trabajo, en Verdad y método Gadamer se reapropia de la concepción kantiana del simbolismo y la desarrolla desde el punto de vista de su posición hermenéutica ${ }^{35}$. En directa relación con ello, a continuación no es nuestro objetivo analizar la concepción del símbolo en Gadamer como tal, sino tan sólo considerar ciertos aspectos directamente vinculados a la recepción de la elaboración kantiana, y mostrar cómo se produce este movimiento de reapropiación que sirve de base al desarrollo de la propia concepción de Gadamer.

Tal como hemos indicado, Gadamer expande en una dirección y con un método propio la elaboración kantiana. Esto llega a tal punto que la misma pregunta central que sirve de base a la investigación trascendental es asumida y refor-

${ }^{35}$ Lo propio de Gadamer puede ser descrito como una consideración del símbolo que se halla orientada por el "giro ontológico de la hermenéutica» siguiendo la guía del lenguaje, tal como es desarrollada en la tercera parte de Verdad y Método. 
mulada por él como "cómo es posible el comprender" ${ }^{36}$. Con ello simultáneamente reconoce, por una parte, el carácter metódico propio de la investigación kantiana del símbolo, pero simultáneamente, por otro, orienta su propio enfoque en una nueva dirección. Gadamer reubica la elaboración kantiana del símbolo en el desarrollo de la comprensión de la obra de arte en tanto «experiencia de la verdad ${ }^{37}$. De este modo la reflexión trascendental del símbolo es proyectada por Gadamer en una ontología del símbolo ${ }^{38}$, la cual, asimismo, se desarrolla sobre la base de una reconstrucción histórica de la evolución semántica de la noción de símbolo. En ésta ya se muestra que el símbolo es algo más que una figura de discurso y se relaciona con la percepción; el símbolo tiene su "propio ser sensible»" ${ }^{39}$. El símbolo "no sólo pertenece a la esfera del logos» ${ }^{40}$, es exhibición y no meramente designación; en otra formulación: "un símbolo no sólo remite sino que presenta» ${ }^{41}$. El símbolo de alguna manera forma parte de la realidad sensible, puesto que "no tiene su significado en la relación con otro significado, sino que su propio ser sensible tiene significado. Es, de un modo primordial aquello donde se puede conocer algo otro" ${ }^{42}$. La elaboración por parte de Gadamer brinda así una nueva perspectiva donde se reunifica la reflexión kantiana sobre el simbolismo. Este aparece ahora en el marco de un trasfondo, donde tiene lugar una «interconexión metafísica entre lo visible y lo invisible» ${ }^{43}$; en esta perspectiva, "el símbolo es la simultaneidad de lo sensible y lo inteligible" ${ }^{44}$. Con ello, Gadamer se reapropia de la concepción de Kant y la reinscribe en un contexto más explícitamente metafísico. Del conjunto de cuestiones que se suscitan a partir de ello, puntualizaré, a modo de conclusión, las tres siguientes.

En primer lugar, quisiera señalar la significación de la elaboración de Gadamer en Verdad y método para la comprensión e interpretación de la filosofía crítica de Kant. En general, esta elaboración puede ser ubicada en el marco de tradición dentro de la cual la filosofía crítica de Kant debe ser vista desde el conjunto

\footnotetext{
${ }^{36} W u M$, xvii.

$37 W u M$, xxix.

${ }^{38} \mathrm{Cf} . W u M, 52$.

39 $W u M, 68$.

40 Ibíd.

${ }^{41} W u M, 146$.

$42 W u M, 68$.

$43 W u M, 69$.

$44 W u M, 70$.
} 
de la obra crítica, lo cual implica una acentuación del papel de la Crítica de la facultad de jugar ${ }^{45}$. Pero, además, la elaboración del lenguaje y el símbolo en Verdad y método puede ser vista como una contribución de relevancia a la comprensión del "problema del lenguaje en Kant». Ello requiere una breve explicación. La postulación de un paralelismo entre el pensamiento crítico y la reflexión de L. Wittgenstein, quien concibiera su investigación «no dirigida a los fenómenos, sino [...] a las 'posibilidades' de los fenómenos»" ${ }^{46}$, planteó a la interpretación de la obra de Kant la cuestión del lugar y valor del lenguaje para la filosofía crítica. Este paralelismo alentó la idea de que Wittgenstein habría trasladado, reinterpretándolo, el idealismo trascendental de Kant del plano de la razón al plano del lenguaje. Así, quedó abierta la posibilidad de examinar la filosofía crítica desde esta nueva óptica. La ausencia de desarrollos explícitos acerca del lenguaje llevó en un primer momento a hablar del "silencio de Kant» al respecto ${ }^{47}$. Con ello quedó planteado, entonces, «el problema del lenguaje» en Kant ${ }^{48}$. La elaboración vista de Verdad y método ofrece pues, una vía de comprensión a dicho problema, en tanto subraya la óptica del simbolismo respecto del lenguaje. Ella, en este sentido, abrió una perspectiva hermenéutica en la interpretación de la obra crítica ${ }^{49}$.

45 Precisamente, en buena medida la línea de interpretación que tiende a subrayar el papel de la Critica de la facultad de juzgar desarrollan, para decirlo brevemente, una orientación metafísica. Cf. R. MALTER: "Main Currents in the German Interpretation of the Critique of Pure Reason since the Beginnings of Neo-Kantianism", Journal of the History of Ideas, vol. XLII, n. 3, 1981, 531551, esp. 542-44; un ejemplo sería la interpretación de Kant por parte de B. Bauch.

${ }^{46}$ L. WITTGEnSTEIN, Philosophische Untersuchungen, Suhrkamp, Fráncfort del Meno, 1960, (\$90) 337. Tomo como expresión de esta argumentación: E. STENIUS: "Wittgenstein as a Kantian Philosopher", en Wittgenstein's Tractatus, Cornell U. Press, Nueva York, 1960, 214-226.

${ }^{47}$ La expresión ha sido empleada por T. de Mauro para referirse precisamente a la actitud de Kant respecto del lenguaje: T. DE MAURO: Introduzione alla semantica, Einaudi, Bari, 1966, 63-66.

${ }^{48}$ Respecto del problema del lenguaje, véase un panorama actual en J. SimON: «Kant», en T. BORSCHE (ed.): Klassiker der Sprachphilosophie, Beck, Múnich, 1996, 233-256. La importancia de la Critica de la facultad de juzgar para la determinación de la reflexión kantiana sobre el lenguaje ha sido ya objeto de detenida consideración: W. BIEMEL: Die Bedeutung von Kants Begründung der Ästhetik für die Philosophie der Kunst, Kölner Universitätsverlag, Colonia, 1959, 74, 81 y 122; B. LIEBRUCKS: Sprache und Bewußstsein, vol. 4: Die erste Revolution der Denkungsart, Beck, Fráncfort del Meno, 1968, 465 y ss., 488 y ss; y J. CARVAJAL CORDON: "El lenguaje como problema filosófico y Critica del Juicio", en R. ARAMAYO y G. VILAR (eds.), En la cumbre del criticismo, Anthropos, Barcelona, 1992, 46-77.

${ }^{49}$ Sirvan como ejemplo de ello: M. RIEDEL: Urteilskraft und Vernunft, Suhrkamp, Fráncfort del Meno, 1989; esp. 7 y 104; y R. MAKKREEL: Imagination and Interpretation in Kant. The hermeneutical Import of the Critique of Judgment, University of Chicago Press, Chicago-Londres, 1990. 
En segundo término, la elaboración de Gadamer de la noción kantiana de símbolo permite precisar la siguiente observación referida a su interpretación en general de la estética de Kant. Una de las cuestiones que Gadamer se plantea en relación con ella es "cómo es posible hacer justicia a la verdad de la experiencia estética y superar la radical subjetivización de la estética, que comenzó con la Critica de la facultad de juzgar estética de Kant ${ }^{50}$. La subjetivización de la estética "comenzó" con la crítica kantiana; esta manera de expresarse permite interpretar que la estética kantiana no es una plena representación de la subjetivización de la estética. Menos aún si nos orientamos por la recepción por parte de Gadamer de la noción de símbolo que analizamos. En ella hay, por así decir, una transición desde lo subjetivo a algo que se presenta en lo objetivo y más allá de ello. Tanto Kant como Gadamer parecen compartir este recorrido, si bien, como hemos visto, este subraya el valor ontológico del símbolo, énfasis que se halla ausente en el análisis kantiano aun cuando en este aparece el carácter transobjetivo del símbolo.

Ello nos conduce, en tercer término, a lo siguiente. En la elaboración hermenéutica de la noción kantiana de símbolo Gadamer sugiere más o menos explícitamente una evaluación general de la perspectiva trascendental en tanto tal. Mientras la elaboración hermenéutica reasume y "supera» el método trascendental, la elucidación ontológica va más allá de los límites que éste se fija en la dimensión básica de la correlación entre sujeto y objeto. Tal vez por ello, la captación de la posición kantiana respecto del símbolo por parte de Gadamer, así como su diferenciación respecto de ella, pueda ser sintetizada en su afirmación de que la posición de Kant respecto del símbolo es «tan precavida como exacta y significativan" ${ }^{51}$.

\footnotetext{
so $W u M, 92$.

$51 W u M, 71$.
} 


\title{
LA HERMENÉUTICA DE H.-G. GADAMER Y LOS IMPLÍCITOS HERMENÉUTICOS DE LA «SEGUNDA CONSIDERACIÓN INTEMPESTIVA» DE F. NIETZSCHE
}

\author{
Luis Enrique De Santiago Guervós \\ Universidad de Málaga
}

\begin{abstract}
RESUMEN. Un ensayo de aproximación de dos hermenéuticas tan ricas como la de Nietzsche y la de Gadamer es un camino fecundo que puede ayudarnos a comprender mejor la hermenéutica de este último, dentro de una tradición que pasa por Nietzsche, y al mismo tiempo a descubrir los implícitos hermenéuticos que oculta la filosofía de Nietzsche. A nadie se le escapa ya que los planteamientos sobre la interpretación de este sentaron las bases a desarrollos hermenéuticos posteriores, pero tal vez no se le haya hecho todavía justicia a Nietzsche respecto a su hermenéutica.
\end{abstract}

Cuando tratamos de confrontar dos hermenéuticas, en apariencia tan radicalmente opuestas, como la de Nietzsche y la de Gadamer, lo primero que puede pensarse es que se trata de reivindicar una en lugar de la otra. Este no es el caso. Lo verdaderamente interesante aquí es abrir una vía de investigación que tome conciencia de la cuestión hermenéutica con otras miras, a fin de poder enriquecer y ampliar el vasto campo de la teoría de la interpretación. En este sentido, tendríamos que pensar en incluir a Nietzsche en esa rica tradición hermenéutica, de la que se le ha excluido no pocas veces, posiblemente por su excesiva "radicalidad" al plantearse el problema fundamental de la interpretación. Pues bien, aquella manera tan radical y "extremista" de la filosofía de Nietzsche, que fascinaba tanto a Heidegger y que marcó de una manera determinante su camino del pensamiento, probablemente no era del gusto de Gadamer. El mismo solía decir con frecuencia que Nietzsche era ciertamente una provocación para todos, y que Heidegger supo darle una respuesta adecuada. Pero no parece, sin embar- 
go, que Gadamer atendiera a esa provocación, a pesar de que, según la apreciación de J. Grondin, «Nietzsche había puesto en marcha una universalización revolucionaria del enfoque perspectivístico e interpretativo, cuya consecuencia puede verse legítimamente en la hermenéutica del siglo $\mathrm{XX}^{\prime \prime}{ }^{1}$. No obstante, Gadamer reconoce con claridad que cuando la cultura occidental se vio sometida a una profunda crítica radical «la hermenéutica se convierte en una cuestión con un significado y alcance universales ${ }^{2}$, y un ejemplo de ese radicalismo lo encuentra precisamente en Nietzsche.

Por eso, siendo consecuentes con la propia hermenéutica de Gadamer, sería importante entablar un diálogo entre Nietzsche y él a fin de poder ser conscientes de sus coincidencias y de sus discrepancias. ¿Por qué hacer aquí una excepción? ¿Realmente Gadamer ha dejado oír la voz de Niezzsche -0 todas las modulaciones de su voz que se han producido a través de la historia más reciente de la filosofía? Si nos aproximamos de una manera benévola a las dos formas aparentemente distintas de enfocar sus planteamientos hermenéuticos, tal vez encontremos algunas coincidencias que puedan ayudarnos a comprender ese hilo conductor inapreciable entre esas dos maneras de abordar el fenómeno de la interpretación.

\section{La crítica al objetivismo científico como punto de partida de una hermenéutica de la finitud en Nietzsche y de Gadamer}

El punto de partida de la hermenéutica de Gadamer, como todos saben, se centró en reivindicar modos de experiencia vitales, que forman parte de la «experiencia humana del mundo", y que trascienden la "pretensión de universalidad de la metodología científica " ${ }^{3}$. Habermas, a pesar de su posición crítica frente a la hermenéutica filosófica de Gadamer, no dejó de señalar que uno de los principales logros de su hermenéutica había sido la crítica al ideal de objetividad de la ciencia, tanto en relación a la ciencia natural, como, sobre todo en relación al historicismo. El ajuste de cuentas con el historicismo, fundamentalmente por sus pretensiones de elevar a categoría de ciencia a las llamadas ciencias del espí-

I. Grondin, Hans-Georg Gadamer. Una biografia, Herder, Barcelona, 2000, p. 29.

2 H.-G. GADAMER, "Hermenéutica como filosofía práctica», en La razón en la época de la ciencia, Alfa, Barcelona, 1981 , p. 69.

${ }^{3}$ H.-G. Gadamer, Verdad y método, $I$, tr. cast. de A. Agud y R. de Agapito, Sígueme, Salamanca, 1977, p. 23 (a partir de ahora, citaremos esta obra como $V M$ ). 
ritu, como es el caso de Dilthey ${ }^{4}$, y su aspiración a grados de certeza y universalidad normalmente atribuidos a la ciencias de la naturaleza, era algo que Gadamer tenía que clarificar en orden a reivindicar un modelo epistemológico que trascendiera los planteamientos de la teoría del conocimiento tradicional de cuño cartesiano. En el fondo, se trataba de desterrar del discurso hermenéutico los elementos dogmáticos que distorsionaban la relación existencial inmediata, la ignorancia de la propia situación histórica o la autodisolución del propio sujeto en aras de lo "dado». Las razones parecían sencillas. La eliminación de las injerencias subjetivas, y la supresión de la distancia entre sujeto y objeto como condiciones de objetividad de toda comprensión, nos llevaba inexorablemente a un dogmatismo con consecuencias imprevisibles sobre la condición humana ${ }^{5}$.

En este contexto, se puede afirmar que uno de los logros inmediatos de la hermenéutica de Gadamer ha sido precisamente la superación de esos planteamientos, mediante un modelo epistémico dialógico-dialéctico, que trata de demostrar la «co-pertenencia» de hombre y tradición como constitutivo esencial de la experiencia hermenéutica. De tal manera que esa pertenencia al pasado ya no será más una limitación de la comprensión objetiva, sino una condición de posibilidad de la misma. Así pues, Gadamer siguiendo a Heidegger y yendo más allá de él, planteaba la cuestión de cómo la hermenéutica, una vez liberada de «las inhibiciones ontológicas del concepto científico de la verdad, puede hacer justicia a la historicidad de la comprensión" " elevando la historicidad del comprender a principio hermenéutico.

Como primera apreciación, podemos decir que hay una coincidencia notable entre el punto de partida de la hermenéutica de Gadamer con el planteamiento inicial de la filosofía de Nietzsche. Si es así, ¿̨se pueden reforzar entonces con Nietzsche los principios hermenéuticos de la filosofía gadameriana? Gadamer, por su parte, piensa que a través de la crítica que hace Nietzsche de las aporías del historicismo, se puede uno ya dar cuenta de las dificultades de la conciencia histórica y de su pretensión de objetividad histórica, y del alcance histórico

${ }^{4}$ Cf. mi trabajo "La hermenéutica metódica. Comprensión y objetividad en las hermenéuticas de F. Schleiermacher, W. Dilthey y E. Betti", en Estudios Filosoficos, 34 (1985), pp. 15-53.

${ }^{5}$ Cf. mi libro Tradición, lenguaje y praxis en la hermenéutica de H. $G$. Gadamer, Servicio de Publicaciones de la Universidad de Málaga, Málaga, 1987, pp. 28-38.

${ }^{6} V M$, p. 331. 
y filosófico de la crítica de Nietzsche al ideal de objetividad. En este sentido, su crítica a la ciencia filológica, como ciencia del espíritu, que busca la objetividad en los textos, es un excelente modelo y referencia para la autocomprensión de la hermenéutica.

Desde sus escritos de juventud, especialmente desde "Homero y la filología clásica", podemos apreciar ese talante anticientificista de Nietzsche, su interés por poner límites a la ciencia, su rechazo a la idea de causalidad y necesidad, y, sobre todo, sus primeras reflexiones sobre la función del arte en la manera de considerar el pasado histórico, es decir, «ver la ciencia desde la perspectiva del arte y de la vida". Todo ello abre una nueva perspectiva de gran calado que encontrará a finales del siglo XX, en las corrientes hermenéuticas, su mejor definición. En los primeros textos de su obra se puede ver ya cómo Nietzsche distingue una historia vista desde la perspectiva científico natural y una historia artística, al servicio de la vida. Por eso estaba convencido, ya desde el principio, de que frente al historiador teórico tiene que ser el poeta ${ }^{7}$ el que escriba la historia, pues de lo contrario «seria una pena - dice Nietzsche- que no fuera el poeta».

En la Segunda Consideración Intempestiva indaga la «utilidad y el perjuicio de la historia para la vida», y esboza, dice Gadamer, "una imagen tremenda de la enfermedad histórica que atacó a su época» ${ }^{8}$. Nietzsche muestra cómo todos los instintos vitales promotores de la vida se corrompen profundamente con esa enfermedad, cómo todas las pautas y valores vinculantes se diluyen cuando se miden con unas normas ajenas y arbitrarias y con tablas axiológicas en constante cambio. Pero la crítica de Nietzsche tiene su lado positivo, como indica Gadamer, ya que proclama "la normatividad de la vida, que calibra la dosis de historia que una cultura puede tolerar sin prejuicio»". Es indudable que en relación

7 Ibíd., p. 284.

${ }^{8}$ Cf. H.-G. GaDAmER, "El problema de la historia en la reciente filosofía alemana" (1943), en Verdad y Método II, Sígueme, Salamanca, p. 38 (a partir de ahora, citaremos esta obra como $V M I I)$.

9 Ibíd. Gadamer nos dice un poco antes (p. 33): «Todavía resuena en nuestros oídos la critica que F. Nietzsche hiciera a la historia en la célebre segunda Consideración intempestiva. ¿Es realmente el sentido histórico esa espléndida ampliación de nuestro mundo que el siglo XIX vio en él? ¿No es más bien señal de que el hombre moderno no posee ya un mundo propio desde que ha aprendido a mirar al mundo con cien ojos a la vez? ¿No se disuelve el sentido de la verdad cuando se hacen conscientes las perspectivas cambiantes en las que esta aparece?". 
con Gadamer, Nietzsche radicaliza aún más esa crítica al historicismo al considerarlo en realidad como una verdadera "enfermedad" o "hipertrofia" que altera la relación de la historia con la vida, y cuestiona el hecho de que la vida pueda ser comprendida, ante todo, como un acontecer histórico para el hombre. Pero Nietzsche, lo mismo que Gadamer, vio que la causa principal de esa enfermedad no era otra sino "la exigencia de que la historia debe ser ciencia" $(1,271)^{10}$, o en otros términos, la oposición que se da "entre vida y sabiduría" $(1,257)$. Y contra las pretensiones de validez y universalismo de la ciencia histórica, Nietzsche opta por una mayor beligerancia que Gadamer y lleva a la historia, como hizo Kant con la ciencia, ante el tribunal de la vida. Tras los fenómenos históricos busca lo que acontece en el fondo de la verdadera realidad, abriendo un escenario nuevo frente al idealismo, a la razón absoluta, al historicismo, al progreso y a la historia, que habían creado una falsa atmósfera de optimismo.

Esto no significa que estemos ante la negación de la historia, ni ante un veredicto contra cualquier manera consciente de guiarnos en la vida, sino ante un veredicto que se vuelve contra los "desordenes" del saber histórico y contra la sobrevaloración de los resultados de la conciencia, en definitiva, contra «los excesos de historia». Nietzsche quiere ante todo invertir aquel principio cartesiano que había abierto las puertas a la modernidad, el "cogito, ergo sum", por el "vivo, ergo cogito" $(1,329)$. La vida, la experiencia vital, es lo que produce el conocer, y este reconocimiento originario es lo que ha de poner limites al propio saber que, a su vez, debe "clavar el aguijón contra sí mismo" $(1,306)$, pues «jestamos condenados a oír eternamente la hipérbole de todas las hipérboles, la palabra, mundo, mundo, mundo, cuando cada uno, de modo sincero, sólo debería hablar del hombre, hombre, hombre!n $(1,312)$. Por eso es por lo que Nietzsche plantea ya en un primer momento una especie de transvaloración en la relación de la vida humana con la historia, en la relación del hombre con el pasado o la tradición.

Nietzsche, que siempre sostuvo una estrecha relación entre conocimiento y praxis vital, entre vivir y conocer $(1,257)$, no podía soportar que la ciencia histórica dejase el pasado en un estado de esclerosis total, en lugar de apropiarse de él en orden a la acción. La ciencia en general, dice, «no puede jamás impartir

${ }^{10}$ Con esta numeración ( $\mathrm{y}$ todas cuantas subsiguen entre paréntesis a lo largo de este escrito) hacemos referencia al volumen y a la página de F. NIETZSCHE, Sämtliche Werke. Kritische Studienausgabe (KSA), ed. de M. Montinari y G. Colli, W. de Gruyter, Múnich, 1980, vol. 1, p. 285. 
órdenes al hombre. Inclinación, amor, placer, dolor, exaltación, creación [...] nada de esto conoce la ciencia. Lo que el hombre vive y experimenta, tiene él que interpretarlo para sí desde alguna parte; y de acuerdo con ello, valorarlo" (7, $429)^{11}$. Y es que la ciencia, siguiendo un modelo holístico, despliega "las redes de un pensamiento global sobre la totalidad del mundo" $(1,97)$, celebrando sus Saturnales, pues sus resultados, por mínimos que sean, son considerados superiores a todas las ideas metafísicas $(1,285)$. Por eso, para Nietzsche, el historicismo es una consecuencia de la cultura socrático-alejandrina y, a su vez, un síntoma de la parálisis de la fuerza vital mediante el saber y el conocimiento, una manera de compensar la debilidad y la falta de vida, producidas por esas "piedras del saber" que son el cientificismo de la historia, y que tan indigestas son para el hombre individual y para su desarrollo y formación.

\section{La hermenéutica de Gadamer y los implícitos hermenéuticos de la «Segunda Consideración Intempestiva»}

Para poder apreciar los implícitos hermenéuticos en la filosofía de Nietzsche $\mathrm{y}$, de esa manera, poder valorarlos frente a la hermenéutica de Gadamer, es necesario proceder hermenéuticamente y dejar que hable de nuevo ese escrito de Nietzsche ya mencionado, la Segunda Consideracion Intempestiva, "Sobre la utilidad y perjuicios de la historia para la vidam. Heidegger, en Ser y Tiempo, salía en defensa de Nietzsche afirmando que la historia puede servir a la vida, pues «la vida es histórica en las raíces mismas de su ser", y decía que Nietzsche lo había comprendido y dicho de un modo penetrante e inequívoco - en la segunda de sus Consideraciones Intempestivas $(1874)^{12}$, en la que «él comprendía más de lo que daba a conocer)además, es él mismo el que hace la historia, y, en este sentido, la historia no es de ninguna manera el espacio temporal que existe desde un principio y para todo futuro, que se llenaría a través de la acción humana. De ahí que al hacer la historia se cree con ello no sólo su propia cultura, sino su propio tiempo y su propia obra. El tiempo y la historia se le abren mediante su propio hacer.

Del escrito de Nietzsche podemos destacar brevemente algunas facetas que pueden orientarnos en nuestra pretensión de valorar aspectos hermenéuticos de

$"$ F. NIETZSCHE, Werke, ed. de Kart Schlechta, Hauser, Múnich, 1977, III, 243.

12 M. HeIDEgGer, Ser y tiempo, tr. de J. E. Rivera, Trotta, Madrid, 2003, p. 411 (SZ, 396). 
su pensamiento y sugerirnos ideas complementarias en relación a la gran obra de Hans-Georg Gadamer. Por ejemplo:

1. Su crítica al objetivismo científico, como ya hemos señalado, que después reivindicaría Gadamer, y que Habermas la considera como una de las mejores contribuciones de la hermenéutica al pensamiento actual.

2. La reivindicación de los griegos presocráticos como modelo de "lo clásico".

3. La manera en que comprende la apropiación del pasado.

4. El significado de la "historia efectual" en su pensamiento.

5. La productividad hermenéutica del concepto de "fuerza plástica».

6. La introducción del elemento crítico y reflexivo frente a la tradición.

7. Reivindicación del arte como modelo de experiencia hermenéutica fundamental.

8. La determinación de la idea de horizonte como elemento más adecuado que el de "prejuicio», etc.

Como se pude apreciar a primera vista, estos aspectos temáticos, que de una $u$ otra manera aparecen en el primer Nietzsche como connotaciones de su crítica al historicismo, pueden sugerirnos esa aproximación Gadamer-Nietzsche, sin caer en el reduccionismo violento que busca contra natura acercar posiciones irreductibles.

Que Gadamer está de acuerdo con Nietzsche, sobre todo en algunos de sus planteamientos de su Segunda consideración Intempestiva, parece evidente. Él mismo hace hincapié en cómo Nietzsche plantea adecuadamente la contradicción entre "la voluntad de formación inmediata que hay siempre en el presente» ${ }^{13} y$ el postulado de Ranke sobre la «autodisolución de la individualidad». Es lo que llama Nietzsche el "talante vital alejandrino", un talante debilitado que es modélico para la conciencia moderna incapaz de hacer una valoración propia de los fenómenos. «La ceguera axiológica - parafrasea Gadamer- propia del objetivismo histórico desemboca así en el conflicto entre el mundo histórico enajenado y las fuerzas vitales del presente». La cuestión hermenéutica fundamental se cifra, entonces, en ver cómo entiende Nietzsche la relación entre pasado y presente, a fin de poder establecer algún nexo con la hermenéutica gadameriana.

13 H.-G. GADAMER, "La universalidad del problema hermenéutico", en $V M, I I$, p. 215. Cf. H. Schröter, Historische Theorie und geschichtliches Handeln. Zur Wissenschaftkritik Nietzsches, Männder, Mittenwald, 1982, p. 236 s. 
Para Nietzsche el pasado, el mundo antiguo, hay que estudiarlo como si fuera también un tú, un ser humano ejemplar, al que se puede imitar, conservar, y criticar. Esta posición respecto al pasado engloba la tesis fundamental de Nietzsche de que la "historia tiene que estar al servicio de la vida" y lo puede hacer de esas tres formas: dando lugar a la historia monumental, anticuaria y critica. Estas tres maneras de relacionarse con el pasado, son algo así como dimensiones historiográficas de la conciencia histórica ${ }^{14}$, y son mencionadas como una especie de estrategia para garantizar al hombre un horizonte histórico en el que pueda vivir, una relación con lo sido, con el pasado. Heidegger decía que esta "triplicidad del saber histórico está bosquejada en la historicidad del Dasein. La historicidad del Dasein hace comprender también hasta qué punto el modo propio del saber histórico debe ser la unidad concreta y fáctica de estas tres posibilidades" ${ }^{15}$. Por lo tanto, Heidegger cree que es importante tener en cuenta que esos tres modos de saber históricos hay que pensarlos en su "unidad fáctica», aunque el propio Nietzsche no dé cuenta de la necesidad de esa tríada ni del fundamento de su unidad. El mismo Gadamer insiste también en que esas tres maneras de entender la autoconciencia histórica hay que comprenderlas dentro de un "equilibrio adecuado" ${ }^{16}$. Por eso, cuando tratamos de elucidar la manera en que Nietzsche mira el pasado, podemos aventurar la hipótesis de que está formulando los distintos momentos de un diálogo permanente con la tradición en el que se considera el modo de ser del objeto, el pasado (Historia monumental), el modo de ser del sujeto, el presente (Historia anticuaria), y el momento de la reflexión, la crítica (Historia crítica). Veamos algunos aspectos de esta especie de "dialéctica hermenéutica»:

En primer lugar encontramos un modelo ejemplar de la "historia que actúa», "historia efectual", en los filósofos preplatónicos y en el modelo de «lo clásico». Nietzsche, como Heidegger después, piensa que los presocráticos, los "pensadores icarios ${ }^{17}$, no son los predecesores de Platón sino sus antípodas; en particular, porque identifican vida y filosofia y de esa manera constituyen una «fuerza» que

14 Cf. E. Mazzarela, Nietzsche e la Storia. Storicita e ontologia della vita, Guida, Nápoles, 2000 , p. 44.

15 M. HeIDEGGER, op. cit., p. 411;SZ, 396.

16 H.-G. GADAMER, "El problema de la historia en la reciente filosofía alemana" (1943), op. cit., p. 38.

$K S A, 8,118$. 
actúa en la historia de una manera ejemplar. Este pasado tiene un modo de ser "intempestivo", lo cual significa en cierta medida la posibilidad de poder "oír" como más próxima y cercana la voz de la tradición. Pero además, el modo de pensar de los primeros filósofos griegos constituye un modelo «ejemplar» que hay que "conservar" 18 , pues Nietzsche estaba convencido de que las ideas griegas habían de ser comprendidas históricamente, a la luz de sus efectos y desarrollos posteriores. Esto explica que a esos "maestros de vida" se les considere «individuos ejemplares", que pueden servir de criterio determinante para nuestro presente, porque poseen una "fuerza» que determina el modo de ser de la historia de la humanidad occidental»" ${ }^{19}$.

Pero también es ejemplar la Antigüedad griega en general, porque fue capaz de transformar aquella fuerza dionisiaca devastadora y dominarla mediante el espíritu apolíneo, que sublimó aquella fuerza bajo el signo del agón. Nietzsche traslada este poder tensional, cuasidialéctico, que se daba entre los griegos en el "certamen" (Wettkampf), o luchas competitivas, a la relación entre presente y pasado. De tal manera que si en la Antigüedad griega el agón, junto con la liberación de nuevas formas de vida, contribuyó a una renovación fundamental, también la Modernidad en lucha competitiva con la Antigüedad debe incrementar las fuerzas para su propia renovación ${ }^{20}$. Con el pensamiento de la lucha competitiva parece estar resuelto lo que se le presenta al joven filólogo Nietzsche como la antinomia de su especialidad: que la Antigüedad es una materia limitada y no inagotable de la filología, y su tarea de comprender mejor la propia época a través de la Antigüedad es, por el contrario, eterna ${ }^{21}$.

Gadamer, lo mismo que Nietzsche, cree que la autocrítica de la filología en relación a sus objetos recuperó el verdadero sentido de "lo clásico» ${ }^{22}$. Lo clásico

${ }^{18}$ F. NIETZSCHE, Die Philosophie im tragischen Zeitalter der Griechen, KSA 1, pp. 801-872, aquí: p. 801 .

${ }^{19}$ H.-G. GADAMER, Die neue Platoforschung (1933), en Gesammelte Werke (en lo sucesivo lo citaremos como GW), vol. 5, pp. 212-229, aquí, p. 228. Cf. también C. H. ZUCKERT, Postmodern Platos. Nietzsche, Heidegger, Gadamer, Strauss, Derrida, University Chicago Press, Chicago, 1996, p. 30.

${ }^{20}$ Cf. M. WISCHKE, "Ist es notwendig, die Vergangenheit zu verstehen? Friedrich Nietzsche und Hans-Georg Gadamer über das "Rätsel der Wertsetzung"", en Perspektiven der Philosophie. Neues Jahrbuch, 28 (2002).

${ }^{21} K S A, 3,3[62], 31$.

$22 V M$, p. 354. 
«es una realidad histórica a la que sigue perteneciendo y estando sometida la conciencia histórica misma" ${ }^{23}$. Es, sin duda, la conciencia de lo permanente, de lo intempestivo que no se somete a una circunstancia temporal. Y esto es así porque, según Gadamer, es una «especie de presente intemporal» que significa «simultaneidad" con cualquier presente. Así pues, lo clásico como pasado es inasequible, pero es algo presente. Recordando a Hegel, "lo clásico es lo que se conserva porque se significa e interpreta a sí mismo" ${ }^{24}$. Nietzsche no tendría ningún inconveniente en ratificar esta relación con el pasado, pues precisamente esa elocuencia, algo que habla por sí mismo, no es un mero objeto que necesite interpretación, sino que continuamente dice algo a cualquier presente. Esa forma intempestiva, por tanto, no requiere que se supere "la distancia histórica» por medio de metodologías científicas o reconstructivas del pasado, sino que, como dice el propio Gadamer de un modo hermenéutico, "está continuamente realizando esta superación con su propia mediación» ${ }^{25}$. Así pues, no basta la reconstrucción, sino la conciencia de la pertenencia a ese mundo y con ello, recíprocamente, la pertenencia de la obra a nuestro mundo, por lo tanto la co-pertenencia de pasado y presente.

Pero para Gadamer es importante hacer notar que ese sentido de lo clásico, que para Nietzsche tenía su modo de ser en el poder de determinación del presente, tal y como se manifiesta en la historia monumental, se reducía en lo esencial a esa "fuerza del decir" (Sagkraft) de una obra del pasado que es, en primer lugar, duradera e inmediata, y en segundo lugar es fundamentalmente «ilimitada". De este modo, Gadamer corroboraba ese principio hermenéutico según el cual un escrito, y más aún un escrito clásico, nunca debe poder ser comprendido del todo, pues siembre cabe la posibilidad de ser comprendido de otra manera, o como diría Nietzsche, desde otra perspectiva o como una nueva interpretación. Con lo cual la validez permanente de lo clásico determina la mediación histórica del pasado con el presente, pues tanto el pasado como el presente se hallan en continua mediación. En Gadamer esto se explica mediante la "conciencia de la historia efectual», en Nietzsche a través de la mediación entre el «sentido normativo" del pasado, y el presente, pues "la necesidad de vida exige lo clásico» ${ }^{26}$,

\footnotetext{
23 Ibíd., 357.

${ }^{24}$ Ibíd., 359.

25 Ibíd.

${ }^{26} K S A$, VII, 29 [29].
} 
y en esa medida «trata el pasado con arte y con una fuerza artística transfiguradora". Por eso en el mismo texto se dice que la vida exige la «equiparación (Gleichsetzen) del presente con el pasado". Pero para comprender mejor la posición de Nietzsche en relación con el pasado y la tradición conviene puntualizar el sentido de la co-pertenencia desde ese concepto tan productivo y fundamental en la hermenéutica de Gadamer como es el de la «conciencia de la historia efectual». Como hemos visto, parece que en Nietzsche se mantiene el carácter de «acción» (Wirkung) de la historia (Geschichte) desde el punto de vista de la historia monumental.

\section{La "apropiación" del pasado por el presente. La funcionalidad del concepto de «fuerza plástica"}

Que la teoría de la historia de Nietzsche, o sus reflexiones sobre la relación entre el pasado y el presente, parecen fundamentarse hermenéuticamente ${ }^{27}$, es algo en lo que algunos estudiosos están de acuerdo. La hermenéutica acentúa que en el acto de la apropiación del pasado, o de la tradición, está la condición de la autorrelación actualizante, sin la que sería imposible la comprensión. En cierto sentido se pude decir que el concepto de Nietzsche de fuerza plástica ${ }^{28}$ puede ser interpretado como concepto hermenéutico de la apropiación y, como tal, habría que decir que se adelanta a algunas de las ideas que posteriormente utilizará Gadamer en su hermenéutica.

Esa "fuerza" no se entiende como un simple «saber interior», sino que es una fuerza que da forma a la historia, como la del artista cuando crea su obra. Es necesaria, porque la historia ya no se forma a sí misma, a diferencia de Hegel. Esa fuerza tiene ya en sus primeros escritos una finalidad transformadora, que Nietzsche puntualiza en los siguientes términos: se trata de "transformar" y "asimilar (einverleiben) lo pasado y lo extraño" en familiar, mediante el ejercicio de la apropiación, "pensando, reflexionando, comparando, separando y sintetizando» $(1,253)$. Este texto tiene gran importancia por varias razones. En primer

${ }^{27}$ Esta es la opinión de K. MEYER en su obra Ästhetik der Historie, Königshausen \& Neumann, Wurzburgo, 1998, p. 126.

28 Posiblemente Nietzsche lo haya tomado de Burckhardt. Lo adopta en un sentido psicológico y lo considera como una propiedad de la juventud (J. BURCKHARDT, Die Kultur der Renaissance in Italien. Ein Versuch, vol. 2, ed. de L. Geiger, Leipzig, 1908, p. 219). 
lugar porque Nietzsche en este caso tiene presente el modelo de la vida, en el mismo sentido que lo utilizó, por ejemplo Hegel, y al que Gadamer se remite ${ }^{29}$ en Verdad y Método. La conservación de la vida implica incorporar en sí lo que existe fuera de ella, pues todo lo vivo se nutre de lo que es extraño. Así pues, el hecho fundamental de estar vivo es la asimilación en la que lo extraño se hace propio, o como diría Gadamer, «familiar». Por lo tanto, la única manera de poder concebir la vitalidad es haciéndose cargo de ella (autorreflexión, autocomprensión, o autoconciencia). En segundo lugar, porque Nietzsche introduce en la apropiación un momento de "reflexión", aunque Gadamer no lo ve del todo claro. Sin embargo, ese tomar conciencia del pasado lo ilustra Nietzsche por medio de una imagen: «el árbol siente sus raíces más de lo que pude verlas, pero ese sentimiento mide toda su grandeza según la grandeza y fuerza de sus ramas visibles» $(1,267)$. En seguida nos viene a la memoria aquella proposición hermenéutica gadameriana según la cual "la conciencia de la historia efectual es finita, en un sentido tan radical que nuestro ser, tal como se ha configurado en el conjunto de nuestros destinos, desborda esencialmente su propio saber de sí mismo" ${ }^{30}$.

Así pues, el propio Nietzsche parece acentuar también el acto de tomar conciencia de aquello que nos determina, aunque no deja de ser cierto que en este caso Nietzsche acentúa el primado del sujeto con el fin de desechar el criterio de la objetividad del historicismo. Esa fuerza del pasado, tal y como la interpreta la historia monumental, es precisamente la que hace que el individuo se enriquezca, porque es la fuerza que hace "crecer a un individuo, a un pueblo, a una cultura", la que "hace curar las heridas, reemplazar lo perdido, generar las formas destruidas» $(1,251)$. Si pudiésemos expresar hermenéuticamente esa idea, podríamos decir con una cierta prudencia que Nietzsche nos está describiendo el modo de ser de la "experiencia hermenéutica». Recordemos cómo Gadamer ponía el énfasis en que el resultado de la experiencia hermenéutica era precisamente que en el individuo se daba un incremento del $\operatorname{saber}^{31}$ y una mayor autocomprensión o, en otros términos, surgiría algo «nuevo» de la confrontación entre el pasado y el presente.

\footnotetext{
${ }^{29} V M$, p. 317.

30 VM, pp.16-17.

$31 V M$, p. 431.
} 
$\mathrm{Y}$ es que para Nietzsche comprender el pasado es un acto creativo ${ }^{32}$, pues lo importante es "hacer historia", y no registrar los hechos tal y como ocurrieron realmente. "Tened el valor de hacer historia", decía Nietzsche $(7,611)$ a modo de imperativo categórico. Pero hacer historia es una tarea propia de artistas: el historiador se asemeja al artista que construye una historia y se sirve del material positivo de la ciencia histórica. Los objetos de la historia hay que tratarlos como si «de los bloques de los hechos históricos nosotros tuviéramos que sacar sólo estatuas» ${ }^{33}$. De esta manera, al mismo tiempo que se comprende el pasado, el hombre se autocomprende, se va creando a sí mismo como una obra de arte que nunca llega a ser perfecta o absoluta, como le hubiera gustado a Hegel, sino que se entiende como un proceso infinito que solo será interrumpido por la muerte, pues al existencia es "un imperfectum que nunca llegar a realizarse de modo completo» $(1,249)$. En este sentido, el propio Gadamer nos remite al momento de la aplicación en la hermenéutica, en la que se identifica comprensión y autocomprensión, pues en realidad, cuando el filólogo trata de comprender un texto dado, lo que hace es «comprenderse a sí mismo en el texto" ${ }^{34}$.

Como se pude apreciar, Nietzsche introduce sin reservas el elemento estético como algo esencial en la confrontación entre el presente y el pasado ${ }^{35}$. En este sentido, y volviendo a la idea de "fuerza plástica", representa una fuerza artística análoga a la fuerza plástica de Apolo, que se basa en el «sometimiento», en la "contención", en poner límites a la fuerza dionisiaca que se desborda. Así pues, la fuerza plástica ejerce una doble función. Por una parte, desde el punto de vista de la historia anticuaria, moldea la tradición o el pasado a tenor de los intereses artísticos del presente, en virtud de esa «capacidad de empatía, de adivinación, de olfatear las huellas casi extinguidas, del instinto de leer correctamente el pasado por más que se haya escrito encima, una rápida capacidad de comprender los palimpsestos, e incluso los polipsestos..." $(1,264)$. Esa fuerza plástica de la historiografía se prefigura también en la imagen del sueño apolíneo. De la misma manera que en la formación de los sueños, el historiador, «recupe-

${ }^{32}$ Cf. C. LIPPERHEIDE, Nietzsches Geschichtstrategien. Die rhetorische Neuorganisation der Geschichte, Königshausen \& Neumann, Wurzburgo, 1999, p. 15.

${ }^{33}$ F. NiETZSCHE, Gesammelte Werke (Musarionausgabe), Múnich, 1920-29, vol. I, p. 283.

${ }^{34} V M$, p. 414.

${ }^{35}$ Sobre la estética de Nietzsche en general, y sobre el modo de ser de la creación artística me remito a mi obra: Arte y poder. Aproximación a la estética de Nietzsche, Trotta, Madrid, 2004. 
ra lo perdido y regenera las formas destruidas" $(1,251)$, "transforma" y "asimiLa". Por eso, para Nietzsche la historia es en grado sumo productiva, en cuanto que la fuerza plástica transforma los hechos históricos y en esa medida el hombre se transforma a sí mismo, pues en realidad, quien cultiva la historia busca en la apropiación del pasado un símbolo de sí mismo, con lo cual se construyen dos relatos, el del pasado y el del yo. Pero, por otra parte, tampoco hay que olvidar que en la historia monumental, que está al servicio de la vida, el yo debe medirse en la grandeza del pasado, aunque también es cierto que sólo se constituye la grandeza del pasado según la medida del yo. Esta dependencia recíproca la compara Nietzsche con la interpretación de un oráculo. El oráculo no tiene ningún sentido objetivo, ofrece al que busca el punto de partida para encontrar el sentido, y aquel que mejor conozca el pasado será el que mejor interprete la voluntad de los dioses.

El hombre, por tanto, necesita la historia para interiorizarse con el propio origen: la necesita para superar lo que ya ha sido, apoyándose en los impulsos de su presente para proyectarse hacia el futuro. Nada del pasado está definitivamente muerto, como un hecho frío y aislado, como pensaban los historicistas: continúa reviviendo en el presente. El pasado siempre se descubre, aunque parezca ya conocido, y se convierte en un nuevo impulso. Ese saber tiene que ser vivo, activo, testimonia la historia verdadera, y jamás se sabe de modo definitivo lo que ha sido. Todo lo que ha sido depende de lo actual, del presente a partir de cuyos impulsos la historia vuelve a ser lo que le corresponde: medida, modelo e imagen. «Sólo desde la fuerza poderosa del presente podéis vosotros interpretar el pasado" $(1,293-4)$. Por eso, los verdaderos historiadores serán aquellos que posean la «fuerza de volver a formular lo ya conocido como algo nunca visto antes» (1, 259). Esos son para Nietzsche los arquitectos del futuro, los que tienen una experiencia superior, los artistas. Los espíritus poderosamente artísticos, «los que son capaces de aprender para la vida y traducir lo que han aprendido en una práctica más elevada" $(1,263)$, los "maestros" que adivinarán lo que es grande en el pasado, pues «jlo semejante se descubre por medio de lo semejante!» $(1,294)$.

De todo lo que hemos dicho, podemos ya deducir que tanto Nietzsche como Gadamer no comparten la actitud de neutralidad del sujeto, o las teorías de la "autodisolución» del sujeto como garantía de la objetividad histórica. Esto para Nietzsche significaría un debilitamiento progresivo de la propia subjetividad, quedando el individuo reducido a pura pasividad, al tratar de anular su posición y 
situación hermenéuticas con tal de salvar la objetividad de los hechos. Todo ello genera, según Nietzsche, un sujeto débil y enfermizo, con la mente embotada (1, 299), que "ha perdido y destruido su instinto" $(1,280)$ incapaz de poder aplicar el pasado al presente, o apropiarse de él, pues esa forma suprema e idealista de objetividad nos remite a un estado en el que el historiador "contempla un acontecimiento de una forma tan pura que no produce sobre su sujeto ningún efecto" $(1,289)$. En este sentido, Nietzsche nos está diciendo que la tradición actúa realmente sobre el sujeto, y que precisamente por eso "el hombre llega a ser hombre cuando transforma la historia pasada en historia presente" $(1,253)$. Pero es consciente, al mismo tiempo, que el pasado no puede llegar a cegar el poder del acto creador en el presente. Por eso, reivindica de una manera firme la necesidad de un sujeto fuerte para medirse con el pasado, pues usólo las personalidades fuertes pueden soportar la historia; los débiles son barridos completamente por ella» (1, 283). Al fin y al cabo, el propio Gadamer nos enseña que en la hermenéutica es necesario, si queremos comprender el pasado o la tradición, «mediarlo con el presente de su propia vida" ${ }^{36}$, para poderlo mantener abierto hacia el futuro.

De este modo, tanto Nietzsche como Gadamer nos enseñan el camino para salir del círculo del ideal de la objetividad de la hermenéutica generado por el ideal de la ciencia y por el historicismo, evitando el «autoolvido" del sujeto y del propio presente. Pero lo cierto es que esa actitud del sujeto no tiene nada que ver con la absolutización del presente a la manera de Hegel, pues ese sujeto, que por otra parte ya no es tal, se relaciona con la tradición o la historia dejando también que la tradición sea, es decir, dejándola que insinúe - no que muestre de un modo absoluto- el "profundo sentido, poder y belleza" que hay detrás de la apariencia de las cosas. Pero para ello, Nietzsche reivindica, como hemos visto, una "gran potencia artística», "un abismarse amoroso en los datos empíricos", "una continua poetización de los tipos dados" $(1,292)$.

Pero para evitar malentendidos Nietzsche completa su comprensión del pasado introduciendo una tercera forma de entender la historia, la historia crítica, un preanuncio de lo que será después su método genealógico. La introducción de ese elemento crítico es interesante, pues en este sentido Nietzsche también se adelanta a lo que posteriormente también sería relevante en el campo de la her- 
menéutica de la Teoría Crítica (Habermas y Apel) y en la polémica que sostuvo con Gadamer al respecto. Nietzsche de una manera gráfica nos dice que hay que llevar también a juicio al pasado. Pero se trata de un juicio muy peculiar, porque no se hace en nombre de la justicia sino en nombre de la vida: "es únicamente la vida quien aquí se expresa, ese poder oscuro e incitante, ese poder que con insaciable afán se desea a sí mismo" $(1,268)$. Por eso el juicio de la vida es siempre injusto, pues su resultado es "condenar el pasado", ya que todo pasado es digno de ser condenado.

Nietzsche, como heredero de la Ilustración ${ }^{37}$, considera que el hombre tiene que emanciparse críticamente de sus vínculos con el pasado, y para ello debe tener primero la fuerza de "destruir y liberarse del pasado, para poder vivir» (1, 269), y utilizarla de vez en cuando. Pero no se trata aquí de una destrucción radical, sino más bien de una "desmitologización», de una «destrucción temporal» que tiene como finalidad que resplandezca aquello que constituye la "grandeza" del pasado. En un texto de la Gaya ciencia vuelve a corroborar esa idea en estos términos: "Todo gran hombre tiene una fuerza retroactiva. Toda la historia se pone por su causa de nuevo en la balanza y mil secretos del pasado salen de sus escondrijos arrastrándose hacia su sol. No hay modo de decir lo que puede todavía llegar a ser una parte de historia. ¡Puede que el pasado esté quizás todavía esencialmente sin descubrir! ¡Se necesitan tantas fuerzas retroactivas todavía! » ${ }^{38}$.

En este sentido, la actitud crítica de Nietzsche está mediatizada por la reflexión en su "conciencia de la historia efectual» - utilizando la terminología de Gadamer-, pues no basta simplemente con afirmar que no podemos «librarnos completamente de esta cadena" $(1,270)$, sino que hay que tomar conciencia de que somos el resultado de las generaciones anteriores, pero también somos el resultado de sus errores y de sus pasiones. $Y$ de una manera categórica afirma que "a pesar de creer que nos hemos emancipado de ellos, de hecho no podemos dejar a un lado que nosotros procedemos de ellos". Pero alcanzar una perspectiva crítica no quiere decir que uno se esté saliendo fuera de la historia para obtener una objetividad universal, tal y como Gadamer respondía a las objeciones de Habermas. Esto no es posible por la complejidad de la historia: nosotros sólo podemos estructurar nuestra comprensión de la historia.

37 Cf. F. NietzsCHE, Aurora, A $\$ 197$, donde habla de la función histórica de la llustración.

38 F. NietZsCHE, Gaya Ciencia, $\$ 34$ (KSA, 3, 404). 
Un ensayo de aproximación de dos hermenéuticas tan ricas como la de Nietzsche y la de Gadamer es un camino fecundo que puede ayudarnos a comprender mejor la hermenéutica de este último dentro de una tradición que pasa por Nietzsche, $\mathrm{y}$ al mismo tiempo a descubrir los implícitos hermenéuticos que oculta la filosofía de Nietzsche. A nadie se le escapa ya que los planteamientos sobre la interpretación de este sentaron las bases a desarrollos hermenéuticos posteriores, pero tal vez no se ha hecho todavía justicia a Nietzsche respecto a su hermenéutica. Las razones parecen obvias. Un autor tan radical y asistemático, que insinúa más que dice, no da facilidades para elaborar un cuerpo hermenéutico estructurado como el de Gadamer; pero eso no tiene que ser un obstáculo para seguir oyendo sus infinitas sugerencias. 